\title{
A (IN)ACESSIBILIDADE NAS BIBLIOTECAS UNIVERSITÁRIAS: a interação entre o bibliotecário de referência e o usuário com deficiência
}

\section{Michelle Karina Assunção \\ Costa \\ Bibliotecária da Universidade Federal de Ouro Preto. Doutoranda em Gestão \& Organização do Conhecimento pela Universidade Federal de Minas Gerais. E-mail: michelleassuncao@gmail.com}

\section{Adriana Bogliolo Sirihal Duarte \\ Professora Associada na Escola de Ciência da Informação da Universidade Federal de Minas Gerais. \\ E-mail: bogliolo@eci.ufmg.br}

\section{RESUMO}

A inclusão de discentes com deficiência nas universidades brasileiras demanda mudanças nos seus espaços, abrangendo as bibliotecas e o processo de formação dos bibliotecários, visando maior eficiência e equidade no atendimento e na prática profissional. 0 presente artigo apresenta parte dos resultados obtidos em pesquisa de dissertação em Ciência da Informação, realizada por meio de uma investigação exploratória de abordagem qualitativa, com o objetivo de refletir sobre a formação formal e continuada do bibliotecário para a interação com usuários deficientes visando à inclusão e acessibilidade nos ambientes das bibliotecas universitárias. Os dados foram coletados por meio de consulta a matriz curricular dos cursos de Biblioteconomia no estado de Minas Gerais, da aplicação de entrevistas semiestruturadas, além do uso da técnica de observação. Foram entrevistados oito bibliotecários de referência de um Sistema de Bibliotecas daquele estado, três alunos com deficiência (auditiva, física e visual), e a Diretoria do Sistema de Bibliotecas. Para análise dos dados utilizou-se a análise de conteúdo das transcrições das entrevistas e dos diários de campo resultantes das observações. Os resultados apontam que a realidade está longe de efetivar o discurso da prática inclusiva e que os usuários passam por muitas dificuldades no cotidiano universitário ao utilizar os serviços da biblioteca.

Palavras-chave: Bibliotecas universitárias. Alunos com deficiência. Acessibilidade. Inclusão. Formação do bibliotecário.

THE (IN) ACCESSIBILITY IN UNIVERSITY LIBRARIES: the interaction between the reference librarian and the disabled user

\section{ABSTRACT}

The inclusion of students with disabilities in Brazilian universities demands changes in their spaces, encompassing libraries and the process of training librarians, aiming for greater efficiency and fairness in care and professional practice. The present paper presents some of the results obtained in a thesis research in Information Science, carried 
out through an exploratory investigation of qualitative approach, with the objective of reflecting on the formal and continuous formation of the librarian for the interaction with disabled users aiming at the inclusion and accessibility in university library environments. The data were collected through consultation of the curricular matrix of the librarianship courses in the state of Minas Gerais, the application of semi structured interviews, as well as the use of the observation technique. We interviewed eight reference librarians from a Library System of that state, three students with disabilities (auditory, physical and visual), and the Library System Board. To analyze the data, we used the content analysis of interview transcripts and field diaries resulting from the observations. The results point out that the reality is far from making the discourse of inclusive practice and that users go through many difficulties in daily life when using the library services.

Key-words: University libraries. Students with disabilities. Accessibility. Inclusion. Librarian formation.

\section{INTRODUÇÃO}

0 presente artigo apresenta parte dos resultados da pesquisa de mestrado intitulada Inclusão e acessibilidade nas bibliotecas universitárias: a formação e atuação do bibliotecário (COSTA, 2015), que realizou uma discussão sobre a prática do profissional bibliotecário e o seu relacionamento com a realidade social brasileira. Mais especificamente, a sua interação com as pessoas com necessidades educacionais especiais (NEE) presentes no ensino superior.

A pesquisa investigou a relação do bibliotecário de referência com alunos com deficiência auditiva, física, e visual (total ou parcial), que é um subgrupo dos alunos com NEE que frequenta e utiliza as bibliotecas universitárias (BUs). Não foram contemplados na pesquisa alunos com altas habilidades (superdotação) ou com deficiências psicológicas, pois isso necessitaria de outro aporte e revisão bibliográfica, o que daria, certamente, origem a nova pesquisa. Consequentemente, com a investigação realizada, questionou-se o quanto as bibliotecas proporcionam acessibilidade ao público de alunos com deficiência auditiva, física ou visual, e como o bibliotecário está apto ou pode melhorar sua formação para atuar com este público.

Os alunos com deficiência necessitam de atendimento psicológico, estrutura física, recursos humanos e tecnológicos para que possam estar e se sentirem inseridos no 
ambiente acadêmico. Dessa forma, os alunos com deficiência precisam ter condições de locomoção, ter recursos humanos capacitados e preparados para recebê-los e atendê-los, tecnologias assistivas para que possam ter autonomia na realização de suas buscas e acesso de informação nas BUs. Portanto, a existência de bibliotecas universitárias orientadas para apoiar tais usuários "é cada vez mais uma exigência, dado estes necessitarem de apoio e orientação personalizada no acesso à informação, recursos e serviços" (MARTINS; MARTINS, 2012, p.7).

A partir do momento que alunos com deficiência estão frequentando as universidades brasileiras, é preciso a reorganização das BUs para os receber, atender e dar acesso às informações; bem como a criação de novos serviços que lhes sejam acessíveis. Isso reforça ao profissional bibliotecário a importância e necessidade de dar atenção à sua educação continuada, de forma que a adquirir competências e habilidades para atendê-los, uma vez que as escolas de Biblioteconomia formam profissionais generalistas.

Todos os alunos, de modo igualitário, independente de sua origem social, sua renda ou que tenham deficiência, têm o direito de acesso aos serviços prestados pelas bibliotecas. Pressupõe-se que o bibliotecário, por ser também um prestador de serviços e por se relacionar com uma diversidade de pessoas, tenha consciência e esteja atento às necessidades e particularidades de seus usuários, de modo que possa ter condições de atender suas demandas.

O objetivo geral da pesquisa foi refletir sobre a formação formal e continuada do bibliotecário para a interação e atendimento aos usuários deficientes, visando à inclusão e acessibilidade nos ambientes das bibliotecas universitárias. Como desdobramento, os objetivos específicos que se apresentaram foram conhecer os desafios encontrados pelos bibliotecários no atendimento ao usuário com deficiência e identificar competências necessárias para trabalhar com este público; investigar quais os fatores motivacionais tendem a levar o bibliotecário de referência a se dedicar na sua formação continuada; discutir o papel do bibliotecário e da biblioteca no contexto da educação inclusiva, bem como o da universidade na formação desse profissional (bibliotecário) para o atendimento a alunos com deficiência. 


\section{A SOCIEDADE INCLUSIVA E O PROFISSIONAL BIBLIOTECÁRIO}

O discurso da sociedade que pretende ser uma sociedade para todos tem exigido a inclusão de pessoas com deficiência em todos os seus espaços, compreendendo também as BUs. Deve-se frisar que uma sociedade inclusiva vai além da garantia de ambientes que sejam adequados a todo o tipo de pessoa, esta sociedade vem fortalecer as atitudes de aceitação das diferenças, valorizando a diversidade humana e enfatizando a necessidade da convivência com pessoas deficientes e a garantia dos direitos de qualquer cidadão (DECLARAÇÃO, 1994; SANTOS, 2005; SASSAKI, 2006; BRASIL, 2013; SILVA; COSTA; CRIVELLARI, 2014).

Ao refletir sobre a prática do profissional bibliotecário diante das mudanças constantes que acontecem na sociedade, considera-se necessário repensar a sua formação para atuar na sociedade inclusiva. Portanto, "esta é uma questão para se repensar os espaços de informação que hoje estão disponíveis nas universidades federais brasileiras" (SILVA; COSTA; CRIVELLARI, 2014, p.2454).

O bibliotecário brasileiro, para Cysne (1993, p. 64) “[...] está aquém das necessidades de seus usuários. Seja pela burocratização do processo de transferência da informação, decorrente da maximização de procedimentos técnicos, ou seja, pela falta de sensibilidade decorrente da impossibilidade do bibliotecário ver-se corno usuário de biblioteca". Outra crítica quanto ao trabalho do profissional bibliotecário é encontrada na obra de Martins (2001, p. 332). Para o autor,

[...] o bibliotecário se transformou, por consequência, nestas últimas décadas, em técnico puro - com todos os inconvenientes e todas as virtudes dessa condição. [...] entre os defeitos, impossível não reconhecer a superestimação dos conhecimentos restritamente técnicos em prejuízo de uma cultura humanística mais vasta [...].

No tocante à formação do bibliotecário, conforme Martins (2001, p. 336) “[...] é preciso fazer dos estudos biblioteconômicos não apenas a fonte de conhecimentos especializados de catalogação e classificação, mas também a origem de largos conhecimentos humanísticos que se costumam designar pelo nome de cultura geral".

As pressões e modificações pelas quais passa a sociedade exigem que o profissional “[...] tenha além da formação adequada, competência e habilidades exigidas pelas tarefas 
a desempenhar e ajustadas ao tempo atual, implicando em um redirecionamento da conduta do profissional, perante os desafios do momento" (BORGES, 2004, p. 57). Isso inclui se sensibilizar e se apropriar da responsabilidade de tornar as bibliotecas acessíveis, incluindo todos os usuários.

A presença de estudantes com deficiência no ambiente universitário propicia discutir se a universidade, as bibliotecas e os bibliotecários, dentre outros envolvidos neste ambiente, possuem condições para recebê-los e atendê-los. "A realidade em que vivemos, dentro de um contexto globalizado, exige dos profissionais de todas as áreas melhor desempenho e mais eficiência" (SILVA; CUNHA, 2002, p. 80). Portanto, o bibliotecário, sendo capaz de se autoavaliar pessoal, profissional e institucionalmente diante das mudanças que se inserem no seu campo de trabalho, atuará de modo mais eficaz possibilitando a aquisição de competências e conhecimentos.

O Bibliotecário de referência deve ter qualidades distintas com uma grande capacidade de síntese e análise a fim de responder às questões dos usuários. Outras qualidades pessoais também são pertinentes como: acessibilidade, inteligência, conhecimento profissional e intelectual, iniciativa, prudência, perseverança, cortesia. Esse profissional vai adquirindo qualificações no cotidiano de suas rotinas de trabalho (SOUZA; FARIAS, 2011, p. 4).

Entende-se que é preciso repensar na ênfase dada a certos conteúdos presentes na formação do bibliotecário no intuito de possibilitar-lhe enfrentar com mais segurança as novas demandas do seu campo de atuação profissional. Presumimos que, no contexto atual, é "necessário que o bibliotecário apegue-se menos às atividades de processamento técnico, e também esteja preparado para a observação atenta ao meio o qual está inserido o qual possibilitará perceber as necessidades dos usuários das bibliotecas e ser capaz de auxiliá-los adequadamente, sobretudo quando esses atores são deficientes" (SILVA; COSTA; CRIVELLARI, 2014, p. 2457-2458).

Destaca-se a necessidade de alteração no perfil do bibliotecário para acompanhar as demandas de trabalho, incluindo os usuários com deficiência. Para os autores Arruda, Martelete e Souza (2000, p. 4-5) “as alterações no perfil profissional não se restringem ao âmbito da qualificação profissional e da gestão do trabalho, mas abrangem o conteúdo e a forma como o trabalho é realizado, como o trabalhador se relaciona e se socializa no ambiente de trabalho. [...] necessita-se de um profissional flexível, apto a atuar em 
situações de trabalho diferenciadas e a mobilizar seu conhecimento em prol da organização".

Conforme identificado na pesquisa, a atualização profissional acontece por vários motivos, seja por interesses pessoais ou profissionais. Os resultados mostraram que estas são questões muito subjetivas do profissional, e vão além do contexto profissional, perpassando questões familiares e individuais de cada bibliotecário.

Partindo das observações supramencionadas dos autores Cysne (1993), Martins (2001), Silva e Cunha (2002), Borges (2004), Souza e Farias (2011), percebe-se que, ainda nos dias de hoje, o bibliotecário brasileiro está aquém das necessidades e demandas dos usuários deficientes das bibliotecas.

\section{ACESSIBILIDADE NAS BIBLIOTECAS UNIVERSITÁRIAS}

A presença de alunos com deficiência no ambiente acadêmico é um desafio a ser enfrentado pelas instituições de ensino superior (IES), e um desafio também para as bibliotecas e para os bibliotecários que realizam a gestão destes espaços, como para aqueles que fazem o atendimento no serviço de referência. Destaca-se que, "[...] não lidar com as diferenças é não perceber a diversidade que nos cerca, os muitos aspectos em que somos diferentes uns dos outros [...]" (SANTOS, 2005, p. 26).

Existem vários usuários nas bibliotecas e de acordo com Silva et al. (2007, p. 107), o usuário da informação pode ser definido como “[...] aquele indivíduo, grupo ou entidade que utiliza os serviços prestados por uma biblioteca, centros de informação[..], e deles tiram algum proveito, modificam suas estruturas cognitivas, comportamentos e desenvolvimento pessoal". Dentre eles temos um usuário particular, que tem deficiência - usuário com necessidades especiais - e que se investigou na pesquisa.

Usuário com necessidades especiais (special needs), que pode ser portador de deficiências visuais, ou ter necessidades físicas específicas ou distúrbios de aprendizagem. 0 sistema deve ter condições para suportar a necessidade especial do usuário (CUNHA, CAVALCANTI, 2008, p. 347).

Esse grupo de usuários pode ter deficiência auditiva, visual, física, intelectual, superdotação, autismo, dentre outras. Diante desses exemplos, é pertinente refletir se os serviços das bibliotecas universitárias são disponibilizados e acessíveis também para os 
usuários com deficiência. Na gestão das bibliotecas e no planejamento de novos serviços, deve-se pensar nesse tipo de usuário que, como qualquer outro, tem o direito de acesso aos serviços prestados.

No Brasil, praticamente, inexiste biblioteca universitária que incorpore ao seu planejamento garantias de acesso pleno a deficientes físicos, prevalecendo barreiras arquitetônicas em suas instalações. Seu conjunto de recursos informacionais, representado através de itens componentes de seus acervos, também é projetado visando ao atendimento daquela comunidade de usuários julgada fisicamente "normal" [...] (SILVEIRA, 2000, p. 3-4).

Cabe destacar que a relação e interação entre o bibliotecário e o usuário são de extrema importância para o serviço de referência, pois este é o mediador entre o usuário que busca por informação e pelos documentos que estão nos acervos das bibliotecas.

A interação (isto é, a interação face a face) pode ser definida, em linhas gerais, como a influência recíproca dos indivíduos sobre as ações uns dos outros, quando em presença física imediata (GOFFMAN, 2009, p. 24).

Portanto, a gestão de uma BU e, consequentemente, as pessoas que realizam atendimentos nas bibliotecas devem atentar para a interação entre os atores envolvidos e para a integração de todos os usuários nos espaços disponibilizados pela BU, tratem-se de espaços físicos ou virtuais.

Mazzota (2005, p. 65) ressalta que reconhecer a importância da participação das pessoas com deficiência no planejamento e na execução dos serviços, produtos e recursos que são destinados a esse público é imprescindível para que possamos ter uma sociedade democrática e inclusiva em todos os seus espaços, efetivando, assim, na prática, o que a legislação brasileira orienta.

\section{MÉTODO}

Como recurso para o desenvolvimento da pesquisa adotou-se o método qualitativo. Groulx apresenta uma passagem que se assemelha ao que se pretendeu com o estudo realizado "[...] a pesquisa qualitativa situa, geralmente, sua contribuição à pesquisa social, na renovação do olhar lançado sobre os problemas sociais e sobre os mecanismos profissionais e institucionais de sua gestão" (GROULX, 2008, p. 96). 
Através do estudo de caso procurou-se esclarecer como os assuntos de inclusão, acessibilidade e a presença de alunos com deficiência no ensino superior impactam no trabalho do profissional bibliotecário e se há demanda por capacitação desse prestador de serviço no contexto das BUs. 0 estudo de caso "[...] consiste no estudo profundo e exaustivo de um ou poucos objetos, de maneira que permite seu amplo e detalhado conhecimento. [...] proporciona uma visão global do problema ou permite identificar possíveis fatores que o influenciam ou são por ele influenciados" (GIL, 2010, p. 38).

0 trabalho realizou também um levantamento documental sobre o tema central e seus desdobramentos através da consulta à matriz curricular dos cursos de Biblioteconomia da Escola de Ciência da Informação (ECI) da UFMG, instituição pública, e do Centro Universitário de Formiga (UNIFOR-MG), instituição particular, que oferecem o curso no estado de Minas Gerais. Verificou-se a matriz curricular dos cursos da UNIFORMG com data de vigência de 01/01/2012, e da ECI/UFMG versão curricular do ano de 2014, para identificar ou não a oferta de disciplinas que abordassem as temáticas de inclusão e acessibilidade.

As técnicas de observação e entrevista semiestruturada em profundidade possibilitaram compreender os assuntos abordados na pesquisa sob a ótica do bibliotecário e do usuário deficiente auditivo, físico e visual, auxiliando na definição das categorias para posterior discussão. Através da observação não participante nos espaços das bibliotecas investigadas foi possível registrar fatos ocorridos nos ambientes analisados, contribuindo para a análise dos dados e discussão dos objetivos que foram propostos.

A amostra da pesquisa contou com a participação de pelo menos 1 (um) bibliotecário de referência das bibliotecas setoriais de uma Universidade mineira que atendessem os cursos por área do conhecimento (Ciências Agrárias, Ciências Biológicas, Ciências da Saúde, Ciências Exatas e da Terra, Ciências Humanas, Ciências Sociais Aplicadas, Engenharias, Linguística, Letras e Artes), totalizando 08 (oito) bibliotecários de referência, 03 (três) discentes com deficiência, e um Diretor do Sistema de Bibliotecas.

Para análise dos dados coletados, fez-se uso da análise de conteúdo dos dados transcritos, tanto as transcrições das observações realizadas e registradas em diário de campo quanto das entrevistas gravadas em áudio. Por meio desta técnica, empreendeuse um estudo minucioso do conteúdo das transcrições, das palavras e frases que as compuseram, procurando dar-lhes sentido, captar as intenções, comparar, avaliar, 
descartar, reconhecer o essencial, e selecionar as categorias. 0 princípio da análise de conteúdo é esclarecer suas diferentes características e extrair sua significação (LAVILLE; DIONE, 1999, p. 214).

A categorização partiu do recorte dos conteúdos em temas na tentativa de responder aos objetivos propostos na pesquisa a partir dos dados coletados (1) nas entrevistas com o discurso dos nossos interlocutores quanto às respostas obtidas, e (2) durante a observação dos espaços das bibliotecas universitárias. Destaca-se que neste artigo apresentam-se detalhes parciais da análise de dados, priorizando os resultados obtidos a partir das entrevistas com bibliotecários.

\section{RESULTADOS}

Apresenta-se no quadro 1 a sequência em que foram realizadas as entrevistas com os oito (8) bibliotecários de referência entre os meses de abril e maio de 2015, a maioria no local de trabalho do bibliotecário. Somente com um bibliotecário não foi possível realizar a entrevista na sua unidade, mas tomou-se o cuidado de conduzi-la em espaço reservado no qual estiveram presentes no momento da entrevista somente o pesquisador e o entrevistado. Verificou-se que todos os bibliotecários entrevistados graduaram-se no curso de Biblioteconomia oferecido pela UFMG em diferentes momentos. Portanto, o quadro apresenta o ano em que eles se formaram que variou desde 1981 até 2009, compreendendo diferentes currículos do curso oferecido por esta instituição.

Quadro 1- Bibliotecários de referência entrevistados

\begin{tabular}{c|c|c}
\hline BIBLIOTECÁRIOS & $\begin{array}{c}\text { ANO DE } \\
\text { CONCLUSAO } \\
\text { DA GRADUAÇÃO }\end{array}$ & $\begin{array}{c}\text { NíVEL DE } \\
\text { ESCOLARIDADE }\end{array}$ \\
\hline B1 & 1986 & Mestrado \\
B2 & 1985 & Especialização (EAD) \\
B3 & 2003 & Especialização \\
B4 & 2004 & Doutorando \\
B5 & 2009 & Especialização \\
B6 & 2004 & Mestrando \\
B7 & 1981 & Especialização \\
B8 & 2004 & Especialização (EAD) \\
\hline
\end{tabular}

Fonte: Dados da pesquisa, 2015.

No quadro 2 estão apresentados os estudantes deficientes que participaram da pesquisa. Apesar de os estudantes com deficiência visual e auditiva pertencerem à mesma 
área de conhecimento (Linguística, Letras e Artes), eles estão matriculados em cursos diferentes. As entrevistas com os estudantes se deram no período de abril a julho de 2015.

Quadro 2 - Estudantes com deficiência entrevistados

\begin{tabular}{|c|c|c|c|}
\hline $\begin{array}{l}\text { ESTUDAN } \\
\quad \text { TES }\end{array}$ & $\begin{array}{c}\text { ÁREA DO } \\
\text { CONHECIMENTO }\end{array}$ & $\begin{array}{c}\text { PERÍODO } \\
\text { (graduação ou } \\
\text { pós-graduação) }\end{array}$ & DEFICIÊNCIA \\
\hline E1 & Linguística, Letras e Artes & $9^{\circ}$ & $\begin{array}{l}\text { Visual (cegueira total) - glaucoma } \\
\text { congênito - nascença }\end{array}$ \\
\hline E2 & Linguística, Letras e Artes & $2^{\circ}$ & $\begin{array}{c}\text { Auditiva (moderada para severa) } \\
\text { - adquirida }\end{array}$ \\
\hline E3 & Exatas e da Terra & Doutorando & Física (cadeirante) \\
\hline
\end{tabular}

Fonte: Dados da pesquisa, 2015.

Realizou-se também uma entrevista com a Diretoria do Sistema de Bibliotecas incluída na amostra ao final da pesquisa, quando se percebeu a necessidade de complementar algumas lacunas de informação.

Visando preservar a identidade dos entrevistados, todos são identificados pela letra B ou E seguida do número de ordem em que foram entrevistados, em que B se refere ao cargo bibliotecário, e E à ocupação de estudante, independente do gênero. Assim, na referência a esses sujeitos, sejam homens ou mulheres, utiliza-se sempre a expressão entrevistado, distinguindo apenas como bibliotecário ou estudante.

Por várias vezes foi necessário reler as transcrições das entrevistas, ouvir novamente as gravações, com o intuito de definir a categorização final para esta análise. Ao final, chegou-se modelo apresentado no quadro 3.

Para este artigo, optou-se por fazer um recorte da análise dos dados, de modo que serão enfatizadas, aqui, as três primeiras categorias de análise, e apenas do ponto de vista dos bibliotecários. Na sequência serão, portanto, apresentados e discutidos trechos das falas dos bibliotecários de referência que ilustram as principais conclusões das três primeiras categorias e suas subcategorias. 
Quadro 3 - Categorias e subcategorias da análise de dados

\begin{tabular}{|c|c|}
\hline Categorias & Subcategorias \\
\hline $\begin{array}{l}\text { 1. Presença de usuários com } \\
\text { deficiência }\end{array}$ & $\begin{array}{l}\text { 1.1 Relacionamento entre bibliotecário e usuário } \\
\text { 1.2 Preconceito, Estigma, Desconhecimento e } \\
\text { Aceitação }\end{array}$ \\
\hline $\begin{array}{l}\text { 2. Tecnologia e/ou serviço } \\
\text { acessível à pessoa com } \\
\text { deficiência }\end{array}$ & $\begin{array}{l}\text { 2.1 Acessibilidade informacional } \\
\text { 2.2 Acessibilidade arquitetônica } \\
\text { 2.3 Acessibilidade comunicacional } \\
\text { 2.4 Acessibilidade atitudinal }\end{array}$ \\
\hline 3. Formação profissional & $\begin{array}{l}\text { 3.1 } \text { Graduação } \\
\text { 3.2 } \\
\text { 3.3 } \text { Formação continuada } \\
\text { Motivacionais/Barreiras }\end{array}$ \\
\hline $\begin{array}{l}\text { 4. Atuação do bibliotecário } \\
\text { na sociedade inclusiva }\end{array}$ & $\begin{array}{l}\text { 4.1 Competências técnicas } \\
4.2 \text { Competências comportamentais } \\
4.3 \text { Autoavaliacão }\end{array}$ \\
\hline $\begin{array}{l}\text { 5. Gestão da biblioteca } \\
\text { universitária }\end{array}$ & $\begin{array}{l}\text { 5.1 Ambiente externo } \\
\text { 5.2 Comunicação organizacional }\end{array}$ \\
\hline
\end{tabular}

Fonte: Dados da pesquisa, 2015.

Abordou-se na primeira categoria a percepção dos bibliotecários a respeito da presença de pessoas com deficiência em dois momentos da sua vida. Primeiro, na época em que os bibliotecários cursavam a graduação, e segundo, atualmente, enquanto profissionais na Universidade. Nem todos os profissionais conseguiram lembrar se na época em que estudavam havia colegas com deficiência, alguns devido ao tempo de formação, outros, por que não souberam informar com precisão. Esta categoria foi subdivida em Relacionamento entre bibliotecário e usuário e o Preconceito, Estigma, Desconhecimento e Aceitação.

Eu me lembro de ter visto um deficiente visual, mas não era da minha turma. Eu nem saberia dizer se ela estava matriculada, eu a via pelos corredores. Não sei se era do nosso curso ou da Letras, que às vezes é passagem de muita gente (B3, 2015).

Estudava na escola, mas eu me lembro dele lá. Ele era assessorado o tempo inteiro pelos colegas. [...] então tinha uma menina que ela andava de braços dados com ele o tempo todo (B2, 2015).

Tinha até uma estudante que tinha um problema de estatura. Não é bem anã não. Mas, tem baixa estatura, tem uma estatura de uma criança (B1, 2015).

Ao se analisar o comportamento e ações descritas pelos bibliotecários no decorrer das entrevistas, pode-se deduzir que aqueles que conviveram durante sua formação com algum colega deficiente, de certa maneira se tornaram profissionais mais sensíveis a essa 
temática. Seus currículos de graduação, conforme se verá na análise da categoria 3.1, não contemplou a discussão da temática acessibilidade e inclusão, portanto apenas a convivência com a deficiência é que lhes propicia a experiência e a sensibilidade para a questão. A subcategoria seguinte corrobora isso. Normalmente, o bibliotecário de referência não é proativo em relação à questão da deficiência. Como se pode observar, quanto à subcategoria Relacionamento entre bibliotecário e usuário foram obtidas as seguintes respostas:

Só se vierem na biblioteca, aí a gente descobre que tem (B1, 2015).

Nossa biblioteca não tem nenhum usuário desse tipo, então nós não deparamos ainda com esse [...]. Em algum momento eu vou deparar, e eu não sei o que fazer $(B 5,2015)$.

No que concerne à subcategoria Preconceito, Estigma, Desconhecimento $e$ Aceitação, percebeu-se diferentes tipos de comportamento em relação à deficiência. Houve bibliotecários que perceberam o preconceito, como se pode ver no depoimento de B1, mas também houve outros que demonstraram a aceitação, tanto por parte dos profissionais quanto dos colegas.

Eu acho que tem preconceito até hoje. Quando ela era estudante na minha sala eu notava preconceito e hoje mesmo, atuando, ainda noto preconceito sabe? Porque eu não sei, as pessoas julgam muito pela aparência das pessoas não é? Acham que elas são incapacitadas, que não raciocinam como uma pessoa normal [...]. É triste! Sabe, então assim, eu notei e noto até hoje, mas infelizmente... $(\mathrm{B} 1,2015)$.

O desconhecimento se fez presente entre quase todos os bibliotecários entrevistados (à exceção da diretoria do Sistema): nenhum bibliotecário conhecia normas e legislação brasileira sobre acessibilidade e inclusão, e mesmo a terminologia a ser utilizada era desconhecida por muitos deles. 0 emprego errôneo da expressão surdomudo para designar o surdo ou da expressão portador de deficiência para designar o deficiente apareceu mais de uma vez.

A Tecnologia e/ou serviço acessível à pessoa com deficiência foi analisada na categoria 2, tendo como desdobramento quatro dimensões de acessibilidade presentes nos espaços das bibliotecas setoriais. Sobre esta questão os bibliotecários disseram: 
Nada assim. Nada implementado assim, não. Esse assunto não está presente nas conversas (sistema de bibliotecas). E acho que é no geral na Universidade não tem isso introduzido. Tirando a [Unidade], que é um caso um pouco à parte do universo (B4, 2015).

Ao se referir à uma unidade específica, o entrevistado está citando um caso de acessibilidade informacional implementado na instituição. Nessa unidade em particular foi implantado um Centro de Atendimento ao Deficiente Visual que tem como principal objetivo oferecer acesso a diferentes formas e fontes de informação aos cegos, com recursos informacionais como lupas, livros em Braille, computadores com leitores de tela, audiolivros, impressora Braille entre outros. 0 entrevistado esclarece que apenas nessa unidade existe esse tipo de atendimento. A Universidade possui um sistema de bibliotecas setorizado, mas embora a direção do sistema de bibliotecas informe que exista um projeto no sentido de tornar inclusivas todas as bibliotecas do sistema, os bibliotecários o desconhecem e, tirando essa unidade, as demais demonstram pouco conhecimento sobre a questão.

Então, quem for construir prédios novos tem de ver no projeto, igual aqui, foi pensado, eu achei estranho, esse elevador. Tem um elevador aqui, mas não é utilizado, nunca vi sendo utilizado, não sei por quê. Então ele é utilizado para descer o carrinho com livro porque o acervo ficou aqui em baixo. Eu achei estranha essa divisão também [...] (B4, 2015).

Ao reportar-se à acessibilidade arquitetônica, B4 demonstra a diferença entre projetar uma biblioteca acessível e reformar uma biblioteca já existente para que ela se torne acessível. Ressalta que a acessibilidade deve ser projetada e implantada para esse fim e exemplifica com a questão do elevador em sua biblioteca, que foi projetado para promover a acessibilidade, mas está sendo utilizado com o fim de transporte de material.

Acessibilidade é um assunto muito importante. Mas ela não faz parte ainda, como deveria fazer, da vida... da rotina das bibliotecas. E aí a gente ficou assim: ah, não, na hora que alguém chegar aqui com alguma deficiência, a gente se prepara. E a gente só fica esperando acontecer. Ainda não me deparei com a necessidade real de implantar uma biblioteca com acessibilidade de fato, mas eu espero que realmente todas tenham possibilidade de fazer isso $(\mathrm{B} 7,2015)$.

Se os depoimentos retratam carência de acessibilidade arquitetônica e informacional, também a acessibilidade atitudinal dos bibliotecários é falha. Sua atitude é passiva. Eles aguardam o aparecimento do usuário deficiente para, então, resolverem o 
que fazer em relação à questão. Não se demonstram preocupados nem proativos, como demonstra o depoimento de B7. Outros depoimentos mostram que o mesmo ocorre em relação à acessibilidade comunicacional: só há um bibliotecário interessado em aprender a Língua Brasileira de Sinais (LIBRAS), por exemplo.

A formação do bibliotecário, discutida na categoria 3 envolve a formação inicial, a graduação, sua formação continuada, pós-graduação, cursos de curta duração, e o seu exercício profissional que tendem a apontar para a necessidade de novas competências, habilidades e atitudes do profissional que atua na função de bibliotecário de referência. Essa discussão abordou também os fatores motivacionais e as barreiras para a formação continuada do bibliotecário. No que se refere à matriz curricular dos cursos de Biblioteconomia no Estado de Minas Gerais, destaca-se que não foi realizada uma análise exaustiva da mesma, mas sim uma consulta no intuito de verificar ou não a presença de disciplinas acerca da acessibilidade, inclusão, entre outros assuntos relacionados a essa temática. 0 que se constatou nas grades curriculares em oferta, a quase ausência de disciplinas relacionadas à temática, confirmou-se pelo depoimento dos entrevistados. Foi de todos eles a percepção de que o curso de graduação em Biblioteconomia não aborda questões de acessibilidade e inclusão.

Educação inclusiva eu só fui ver na prática $(B 5,2015)$.

Eu não tive nenhuma formação não é? Porque eu fiz o curso e nunca teve uma disciplina. Eu não me lembro de ter feito nenhuma disciplina que preparasse para trabalhar com pessoas assim não, com deficiência não. Eu não me lembro de abordagens assim no curso (B2, 2015).

Não. Ninguém nunca (abordou), mesmo com a presença dela (estudante cega) durante o curso que ela fez com a gente. Ela foi até o final, ela formou, e nunca foi falado (sobre inclusão/acessibilidade)[...] (B4, 2015).

As pessoas se acomodam. Passei em um concurso, estou ótima, não preciso fazer muita coisa. Mas tem tanta coisa para você aprender, o mundo lá fora está se movimentando, e as pessoas estão paradas sentadas nas suas cadeirinhas, sem fazer nada [...] $(\mathrm{B} 5,2015)$.

Eu penso que podem ser questões financeiras, por exemplo, questões de conhecimento de outro idioma [...]. Mas cada pessoa tem um problema, não posso por isso ou por aquilo. Talvez até a oferta naquilo que a pessoa tem interesse e não tem oferta daquilo que ela quer (B2, 2015).

Faltam cursos formais não é? [...] porque eu até tento me virar, mas é insuficiente a formação que eu tenho. Fazer um curso de Libras, fazer um curso de Braille, sabe (B1, 2015). 
Todos os entrevistados enfatizaram, também, a necessidade da educação continuada, seja através de cursos de pós-graduação, seja através de cursos de atualização. Muitos se envolveram, inclusive, em cursos de pós-graduação, mas nenhum relacionado à temática de acessibilidade/inclusão. Esta questão não tem sido foco de discussão entre os colegas de trabalho, não tem sido abordada no Sistema de Bibliotecas, segundo os dados das entrevistas. Embora demonstrem a necessidade de buscar conhecimento, os bibliotecários apontam também as barreiras para essa busca: comodismo, questões financeiras, problemas individuais, barreiras relacionadas ao conhecimento de outro idioma.

\section{CONSIDERAÇÕES FINAIS}

Por meio da pesquisa realizada foi possível trazer à tona um assunto com o qual os bibliotecários de referência não estão muito familiarizados, a inclusão de alunos com deficiência no ensino superior e, consequentemente, como usuários das bibliotecas universitárias.

Cabe às BUs a eliminação de diversas barreiras como a arquitetônica para pessoas com deficiência física e/ou mobilidade reduzida, sinalização em Braille e piso tátil para os cegos, obras em Braille, terminais de consultas com programa de voz e com monitores maiores, incluindo o teclado em Braille, informações em tamanhos ampliados para pessoas com baixa visão, equipe treinada e proativa para auxiliar os usuários, conhecimento em Libras, dentre outros pontos, nos espaços de todas as bibliotecas setoriais, para que o usuário possa utilizar a biblioteca que ele quiser. Por se tratar de um Sistema de Bibliotecas, presume-se que as partes tenham que estar preparadas, coordenadas entre si, para formar um todo inclusivo e que funciona como estrutura organizada e com o mesmo pensamento.

Constata-se que o grupo de profissionais que participaram da pesquisa e que hoje atua na função de bibliotecário de referência necessita de capacitação, de formação continuada para atender e se relacionar com a pessoa com deficiência.

Verificou-se que os profissionais não possuem formação na temática da educação inclusiva, área que compreende também as bibliotecas universitárias e o profissional da informação. Identificou-se que os principais desafios dos bibliotecários com os usuários 
com deficiência são a falta de conhecimento da legislação brasileira sobre a questão, da Língua Brasileira de Sinais (Libras) para comunicar com o usuário surdo, em como abordar/interagir com o deficiente, seja o seu desconhecimento de tecnologias assistivas para uso dos serviços e produtos das bibliotecas, bem como para a autonomia dos usuários nestes espaços. Estes aspectos são maximizados devido principalmente à falta de convivência com a pessoa deficiente.

Quanto aos fatores motivacionais que tendem a levar o bibliotecário de referência a se dedicar à sua formação continuada, identificamos a busca de conhecimento para aplicar no seu trabalho, os usuários das bibliotecas, e situações de trabalho que deixaram a desejar no atendimento ao público, como sendo aspectos importantes para o bibliotecário dar continuidade ao seu processo de aprendizagem. Verifica-se novamente que, dos aspectos citados, nenhum inclui a pessoa com deficiência.

Infelizmente, a prática ainda está longe de efetivar o discurso de sociedade inclusiva, os usuários com deficiência auditiva, física e visual passam por muitas dificuldades no seu dia a dia no ambiente universitário. Estes usuários muitas vezes precisam de ajuda para desenvolver suas atividades acadêmicas ou até se locomoverem nas dependências da universidade e da biblioteca. É preciso entender que as pessoas são diferentes e têm necessidades distintas.

A realidade social do bibliotecário é construída no seu dia a dia com a interação com os mais variados atores, entre os quais deveriam estar incluídos também atores com deficiência, ainda sendo estes uma minoria na Universidade. Considera-se, então, que são necessárias novas pesquisas para refletir sobre a formação do bibliotecário, a matriz curricular dos cursos de Biblioteconomia, sensibilizar para a interação e convivência com pessoas deficientes, além de provocá-los a discutir a inclusão e a acessibilidade como aspectos de sua responsabilidade no âmbito das bibliotecas, sejam elas escolares, universitárias, públicas, comunitárias.

\section{REFERÊNCIAS}

ARRUDA, M. da C. C.; MARTELETO, Regina Maria; SOUZA, Donaldo Bello de. Educação, trabalho e o delineamento de novos perfis profissionais: o bibliotecário em questão. Ci. Inf., Brasília, v. 29, n. 3, p. 14-24, set./dez. 2000. Disponível em: <http://www.scielo.br/pdf/ci/v29n3/a02v29n3.pdf >. Acesso em: 15 maio 2014. 
BORGES, M. A. G. O profissional da informação: somatório de formações, competência e habilidades. In: BAPTISTA, Sofia Galvão; MUELLER, Suzana Pinheiro Machado (org.). Profissional da informação: o espaço de trabalho. Brasília: Thesaurus, 2004

BRASIL. Estatuto da pessoa com deficiência. 2013. Disponível em: $<$ http://www.pessoacomdeficiencia.gov.br/app/sites/default/files/arquivos/\%5Bfield generico imagens-filefield-description\%5D 93.pdf>. Acesso em: 20 abr. 2015.

COSTA, M. K. A. Inclusão e acessibilidade nas bibliotecas universitárias: a formação e atuação do bibliotecário. 2015. 163 f. Dissertação (Mestrado em Ciência da Informação). Universidade Federal de Minas Gerais), Belo Horizonte, 2015.

CUNHA, M. B. da; CAVALCANTI, C. R. de O. Dicionário de biblioteconomia e arquivologia. Brasília: Briquet de Lemos, 2008.

CYSNE, F. P.. Biblioteconomia: dimensão social e educativa. Fortaleza: EUFC, 1993.

DECLARAÇÃO de Salamanca. 1994. Disponível em:

<http://portal.mec.gov.br/seesp/arquivos/pdf/salamanca.pdf>. Acesso em: 10 jan. 2014.

GIL, A. C. Como elaborar projetos de pesquisa. 5. ed. São Paulo: Atlas: 2010.

GOFFMAN, E. A representação do eu na vida cotidiana. Petrópolis: Vozes, 2009.

GROULX, L. H. Contribuição da pesquisa qualitativa à pesquisa social. In POUPART, Jean et al. A pesquisa qualitativa enfoques epistemológicos e metodológicos. 2. ed. Petrópolis: Vozes, 2008.

LAVILLE, C.; DIONNE, J. A construção do saber: manual de metodologia da pesquisa em ciências humanas. Belo Horizonte: Editora UFMG, 1999.

MARTINS, W. A palavra escrita: história do livro, da imprensa e da biblioteca. 3. ed. São Paulo: Ática, 2001.

MARTINS, A. B.; MARTINS, A. Bibliotecários de instituições de ensino superior quebram barreiras. Actas do Congresso Nacional de Bibliotecários, Arquivistas e

Documentalistas, n. 11, 2012. Disponível em:

<http://www.bad.pt/publicacoes/index.php/congressosbad/article/view/466. $>$ Acesso em 15 jul. 2014.

MAZZOTA, M. J. S. Educação especial no Brasil: história e políticas públicas. 5. ed. São Paulo: Cortez, 2005.

SANTOS, M. S. dos. Pedagogia da diversidade. São Paulo: MEMNON, 2005.

SASSAKI, R. K. Construindo uma sociedade para todos. Rio de Janeiro: WVA, 2006. 
SILVA, A. C. P. da. et al. Déficit Informacional: obstáculos no uso de canais (in)formacionais por docente do programa de pós-graduação em economia -

PPGE/UFPB. Inf. \& Soc.:Est., João Pessoa, v.17, n.3, p.107-117, set./dez. 2007. Disponível em: <http://www.ies.ufpb.br/ojs/index.php/ies/article/view/977>. Acesso em: 26 mar. 2014.

SILVA, R. A.; COSTA, M. K. A.; CRIVELLARI, H. M. T. A formação do bibliotecário para atuar na sociedade inclusiva. In: ENCONTRO NACIONAL DE PESQUISA EM CIENCIA DA INFORMAÇAO, 2014, Belo Horizonte. Anais... Disponível em:

<http://enancib2014.eci.ufmg.br/documentos/anais/anais-gt6>. Acesso em: 20 abr. 2015. p. 2740-2759.

SILVA, E. L. da; CUNHA, M. V. da. A formação profissional no século XXI: desafios e dilemas. Ciência da Informação, Brasília, v. 31, n. 3, p. 77-82, set./dez. 2002. Disponível em: $<$ http://www.scielo.br/scielo.php?script=sci arttext\&pid=S010019652002000300008 >. Acesso em: 26 mar. 2014.

SILVEIRA, J. G. da. Biblioteca inclusiva?: repensando sobre barreiras de acesso aos deficientes físicos e visuais no sistema de bibliotecas da UFMG e revendo trajetória institucional na busca de soluções. IN: SEMINÁRIO NACIONAL DE BIBLIOTECAS UNIVERSITÁRIAS. Anais,2000. Disponível em: <http://snbu.bvs.br/snbu2000/docs/pt/doc/t081.doc>. Acesso em 25 mar. 2014.

SOUZA, M. N. A. de; FARIAS, K. M. Bibliotecário de referência e a competência informacional. In.: CONGRESSO BRASILEIRO DE BIBLIOTECONOMIA, DOCUMENTAÇÃO E CIÊNCIA DA INFORMAÇÃO, 24., Anais, 2011, Alagoas. Disponível em: <http://www.repositorio.ufc.br/bitstream/riufc/10377/1/2011 eve mnadesousa.pdf>. Acesso em: 26 ago. 2014. 